\title{
Spontaneous Seizures and Loss of Axo-Axonic and Axo- Somatic Inhibition Induced by Repeated Brief Seizures in Kindled Rats
}

\author{
Umit Sayin, ${ }^{1 \star}$ Susan Osting, ${ }^{2 \star}$ Joshua Hagen, ${ }^{1 \star}$ Paul Rutecki, ${ }^{1,3,4}$ and Thomas Sutula ${ }^{1,2}$ \\ Departments of ${ }^{1}$ Neurology, ${ }^{2}$ Anatomy, and ${ }^{3}$ Neurological Surgery, University of Wisconsin, and ${ }^{4}$ The William S. Middleton Veterans Administration \\ Hospital, Madison, Wisconsin 53792
}

Repeated brief seizures evoked by kindling progressively increase seizure susceptibility and eventually induce spontaneous seizures. Previous studies have demonstrated that the initial seizures evoked by kindling increase paired-pulse inhibition at 15-25 msec interpulse intervals in the dentate gyrus and also induce apoptosis, progressive neuronal loss, mossy fiber sprouting, and neurogenesis, which could potentially alter the balance of excitation and/or inhibition and modify functional properties of hippocampal circuits. In these experiments, paired-pulse inhibition in the dentate gyrus was reduced or lost after $\sim 90-100$ evoked seizures in association with emergence of spontaneous seizures. Evoked IPSCs examined by single electrode voltage-clamp methods in granule cells from kindled rats experiencing spontaneous seizures demonstrated altered kinetics (reductions of $\sim 48 \%$ in $10-90 \%$ decay time, $\sim 40 \%$ in $\tau$, and $\sim 65 \%$ in charge transfer) and confirmed that decreased inhibition contributed to the reduced paired-pulse inhibition. The loss of inhibition was accompanied by loss of subclasses of inhibitory interneurons labeled by cholecystokinin and the neuronal GABA transporter GAT-1, which project axo-somatic and axo-axonic GABAergic inhibitory terminals to granule cells and axon initial segments. Seizure-induced loss of interneurons providing axo-somatic and axo-axonic inhibition may regulate spike output to pyramidal neurons in CA3 and could play an important role in generation of spontaneous seizures. The sequence of progressive cellular alterations induced by repeated seizures, particularly loss of GABAergic interneurons providing axo-somatic and axo-axonic inhibition, may be important in the development of intractable epilepsy.

Key words: hippocampus; dentate gyrus; GABA; CCK; GAT-1; damage; epilepsy

\section{Introduction}

Neural circuits undergo structural and functional alterations in response to neural activity in both development and adulthood. In the developing nervous system, experience-dependent activity precisely refines patterns of connectivity to form functional circuits and networks (Catalano and Shatz, 1998; Penn and Shatz, 1999; Swann et al., 2001). In the adult nervous system, synapses undergo use-dependent alterations in synaptic efficacy such as long-term potentiation and long-term depression. In response to intense synchronous neural activity during seizures, neural circuits undergo a complex variety of immediate and long-lasting molecular and cellular alterations that induce progressive, cumulative, and permanently increased susceptibility to additional seizures, a phenomenon of circuit plasticity referred to as kindling (Goddard, 1969; Goddard et al., 1969). Kindling has been extensively investigated as a model of temporal lobe epilepsy (Majkowski, 1999; McNamara, 1999; Mody, 1999; Dalby and Mody, 2001; Sutula, 2001) and is a property of activitydependent plasticity in cortical, brainstem, and limbic circuits in

\footnotetext{
Received July 25, 2002; revised Dec. 3, 2002; accepted Dec. 9, 2002.

This work was supported by National Institute of Neurological Disorders and Stroke Grant R01 25020 and Veterans Administration research.

*U.S., S.O., and J.H. contributed equally to this work.

Correspondence should be addressed to Dr. T. Sutula, Department of Neurology, H6/570, University of Wisconsin, 600 Highland Avenue, Madison, WI 53792. E-mail: sutula@neurology.wisc.edu.

Copyright $\odot 2003$ Society for Neuroscience $\quad 0270-6474 / 03 / 232759-10 \$ 15.00 / 0$
}

species ranging from amphibians to primates (Wada et al., 1975, 1978; Morrell and Tsuru, 1976; Cain and Corcoran, 1980).

Repeated seizures evoked by kindling predictably induce permanent structural and functional reorganization of the dentate gyrus and hippocampus (McNamara, 1999; Mody, 1999; Sutula, 2001). The initial seizures evoked by kindling increase NMDAdependent excitatory synaptic transmission in granule cells of the dentate gyrus (Sayin et al., 1999; Behr et al., 2001) and also induce a sustained increase in $\mathrm{GABA}_{\mathrm{A}}$-dependent inhibition demonstrated by a variety of physiological measurements (Tuff et al., 1983a,b; Oliver and Miller, 1985; de Jonge and Racine, 1987; Stringer and Lothman, 1989; Otis et al., 1994; Buhl et al., 1996; Nusser et al., 1998). This initial increase in inhibition appears paradoxical in that kindling gradually and permanently increases seizure susceptibility, but is also consistent with evidence suggesting that the dentate gyrus filters neocortical and entorhinal activity converging into the CA3 region of the hippocampus (Lothman et al., 1992; Behr et al., 1998, 2001). Repeated brief kindled seizures induce apoptosis and neuronal loss in the dentate gyrus and hippocampus (Cavazos and Sutula, 1990; Cavazos et al., 1994; Bengzon et al., 1997; Pretel and Piekut, 1997; Dalby et al., 1998; Kotloski et al., 2002), which are accompanied by sprouting of mossy fiber axons (Sutula et al., 1988, 1998; Represa et al., 1989; Cavazos et al., 1991), reorganization of synaptic connectivity with formation of recurrent excitatory circuits (Wuarin and Dudek, 1996, 2001; Lynch and Sutula, 2000), and gliosis (Adams et al., 1998). The pattern of neuronal loss induced by kindling 
resembles hippocampal sclerosis (Cavazos et al., 1994; Kotloski et al., 2002), the most common lesion observed in human temporal lobe epilepsy, and the associated sprouting, gliosis, and progressive memory deficits induced by kindling are also prominent features in human temporal lobe epilepsy (Sutula et al., 1995; Dalby and Mody, 2001; Sutula, 2001).

The structural and functional alterations induced by kindling are eventually accompanied by the emergence of spontaneous seizures (Wada et al., 1975, 1978; Pinel and Rovner, 1978). In this advanced stage, kindled animals demonstrate recurring spontaneous seizures, the defining feature of epilepsy. The specific molecular and cellular alterations in hippocampal circuits associated with the emergence of spontaneous seizures are of interest, because these changes represent an advanced or even an end-stage of a continuum of slowly evolving activity-dependent, seizureinduced alterations. These changes are also of potential clinical importance for understanding how seizure-induced alterations may contribute to intractable human temporal lobe epilepsy.

In this study, the emergence of spontaneous seizures in kindled rats was associated with the loss of inhibition in the dentate gyrus accompanied by seizure-induced reduction in specific subclasses of GABAergic interneurons labeled by cholecystokinin (CCK) and the neuronal GABA transporter (GAT-1). These interneuron subclasses provide axo-somatic and axo-axonic inhibition of the granule cell spike output to CA3 (Leranth and Frotscher, 1986; Halasy and Somogyi, 1993; Freund and Buzsaki, 1996; Ribak et al., 1996) and would be expected to play a critical role in controlling propagation of activity from the dentate gyrus into CA3. Preliminary results have been published previously in abstract form (Sutula et al., 2000).

\section{Materials and Methods}

\section{Surgical and kindling procedures}

Adult male Sprague Dawley rats (250-350 gm; Harlan, Madison, WI) were anesthetized with ketamine $(80 \mathrm{mg} / \mathrm{kg}$, i.m. $)$ and xylazine $(10 \mathrm{mg} /$ $\mathrm{kg}$, i.m.) and stereotaxically implanted with an insulated stainless-steel bipolar electrode for stimulation and recording. The electrode was implanted in either the olfactory bulb ( 9 anterior, 1.2 lateral, 1.8 ventral with respect to bregma) or the perforant path $(8.1 \mathrm{~mm}$ posterior, $4.4 \mathrm{~mm}$ lateral, 3.5 ventral with respect to bregma), and was fixed to the skull with acrylic.

After a 2 week recovery period after electrode placement, the unrestrained awake implanted rats received twice daily kindling stimulation ( $5 \mathrm{~d}$ per week) with a $1 \mathrm{sec}$ train of $62 \mathrm{~Hz}$ biphasic constant-current 1 msec square wave pulses. The stimulation was delivered at the lowest intensity that evoked an afterdischarge (AD) according to standard procedures (Sutula and Steward, 1986; Cavazos et al., 1991). The electroencephalogram was recorded from the bipolar electrode that was switched to the stimulator for the delivery of kindling stimulation. Evoked behavioral seizures were classified according to standard criteria and ranged from class I seizures (behavioral arrest) to class $\mathrm{V}$ seizures (bilateral tonic-clonic motor activity with loss of postural tone) (Sutula and Steward, 1986), which are comparable with partial complex seizures with secondary generalization. Kindled rats were killed at a minimum of $18 \mathrm{hr}$ after the last evoked seizure for anatomical or physiological analysis. All procedures were reviewed and approved by the Research Animal Resources Committee (University of Wisconsin).

\section{Monitoring for spontaneous seizures}

Pilot observations in rats undergoing kindling revealed that spontaneous seizures were commonly observed in rats that experienced $\sim 90-100$ evoked class V seizures during routine twice daily periods of observation before kindling stimulation, but were only rarely observed in kindled rats with fewer evoked seizures. This unsuspected observation suggested that the stage of $\sim 90-100$ evoked class V seizures was a period of transition to a state with spontaneous seizures. When spontaneous seizures were ob- served during routine handling, no stimulation was delivered. A subset of rats that had experienced $\geq 90$ seizures evoked by kindling was therefore closely observed for the occurrence of spontaneous seizures by a behavioral monitoring procedure and compared with normal age-matched controls and kindled rats with $<90$ evoked seizures. The monitoring procedure consisted of visual observation by trained observers for $8 \mathrm{hr}$ daily ( $5 \mathrm{~d}$ per week) to identify spontaneous behavioral class $\mathrm{V}$ seizures consisting of bilateral tonic-clonic movements accompanied by loss of postural tone. Kindled rats were regarded as having reached a stage of spontaneous kindled seizures after a single spontaneous class $\mathrm{V}$ seizure was observed. Another subset of kindled rats was also monitored by the same procedures until three recurring spontaneous class $\mathrm{V}$ seizures were observed.

\section{Hippocampal slice recordings}

Kindled and age-matched normal rats were anesthetized with ether, and the brains were removed rapidly and placed into ice-cold artificial CSF (ACSF) with the following composition (in $\mathrm{mM}$ ): $124 \mathrm{NaCl}, 4.5 \mathrm{KCl}, 1.25$ $\mathrm{NaH}_{2} \mathrm{PO}_{4}, 2 \mathrm{MgSO}_{4}, 26 \mathrm{NaHCO}_{3}, 2 \mathrm{CaCl}_{2}$, and 10 glucose. Transverse hippocampal slices were cut with a vibratome or McIlwain tissue chopper at a thickness of $400 \mu \mathrm{m}$ and transferred to an interface-recording chamber containing oxygenated with $95 \% \mathrm{O}_{2}-5 \% \mathrm{CO}_{2}$ ACSF at $31-32^{\circ} \mathrm{C}$. Orthodromic synaptic responses were recorded in the granule cell layer of the dentate gyrus with extracellular borosilicate electrodes containing $2 \mathrm{M} \mathrm{NaCl}$ (impedance of 5-10 M $\Omega$ ). The responses were evoked by monopolar constant-current stimuli ( $50 \mu \mathrm{sec}$ duration) delivered by electrodes placed in the stratum moleculare of the dentate gyrus in the region of the perforant path. Slices that showed maximum field EPSPs of $<1 \mathrm{mV}$ were discarded. Input-output curves were generated using a sequence of increasing stimulation intensities ranging from below threshold for the population EPSP to supramaximal. Evoked responses were recorded, stored, and analyzed using a Digidata 1200 AD converter, pClamp 6.02, and Clampfit 6.02 (Axon Instruments, Foster City, CA).

Paired-pulse measurements. Paired-pulse responses were evoked by the application of a pair of $0.05 \mathrm{msec}$ test pulses at interpulse intervals of 15-350 msec using the lowest stimulus intensity that evoked the maximum population-spike response. The population-spike amplitude evoked by the second pulse was expressed as a fraction of the maximum response evoked by the first pulse of each pair. Pulse pairs were applied at $0.03 \mathrm{~Hz}$.

Single-electrode voltage-clamp measurements of evoked IPSCs. IPSCs were recorded by single-electrode voltage-clamp methods in transverse slices of hippocampus and dentate gyrus that were removed from a subset of kindled and age-matched adult rats. Recording and analysis of kinetics of IPSCs in neurons of 1- to 2-year-old kindled and age-matched control rats are technically difficult and usually preclude patch-clamp methods. However, single-electrode voltage-clamp methods have been successfully used at advanced stages of kindling (Sayin et al., 1999). Recordings were obtained in hippocampal slices as in preceding sections, with an Axoclamp 2B amplifier in the single-electrode voltage-clamp mode at a switching frequency of $3-5 \mathrm{kHz}$. A separate oscilloscope was used to adjust capacitance compensation and sampling rate. Voltageclamp recordings in granule cells were obtained using borosilicate electrodes $\left(25-40 \mathrm{M} \Omega\right.$ ) filled with $2 \mathrm{M}$ Cs-acetate to block $\mathrm{K}^{+}$conductance and $50 \mathrm{~mm}$ QX314 to block action potentials. Monosynaptic IPSCs recorded in the presence of $20 \mu \mathrm{M}$ DNQX and $50 \mu \mathrm{M}$ APV to block EPSCs were evoked by a stainless-steel bipolar stimulating electrode placed in the granule cell layer as close as possible to the recording electrode to directly activate axons of interneurons projecting to the recorded granule cell. The stimulation electrode was typically within $1 \mathrm{~mm}$ of the site of the recording electrode, and constant-current stimulus pulses of $50 \mu \mathrm{sec}$ duration were delivered at a range of intensities. The input-output relationship was determined, and the minimum intensity that evoked the maximal current was used. This standardized stimulus intensity minimized variability introduced by using the range of intensities that evoke a supramaximal response or the intensity that evokes $50 \%$ of maximal response, and did not significantly differ between control and kindled rats. IPSCs were recorded at a range of holding potentials from -90 to 30 $\mathrm{mV}$ in $10 \mathrm{mV}$ steps. Recordings that demonstrated voltage-dependent contaminants such as regenerative currents indicated by escape voltage 
transients or clear polysynaptic components were excluded. The evoked currents were stored and analyzed using pClamp 6.02, Clampex 6.02, and Clampfit 6.02 for analysis of $10-90 \%$ rise time constants, decay time constants, and signal analysis. Charge transfer was calculated as the integrated area under the curve of evoked synaptic current from the stimulus to $250 \mathrm{msec}$ at a holding potential of $-40 \mathrm{mV}$, which produces outward current. These methods were successful for recording synaptic currents in granule cells from relatively old kindled rats and age-matched controls (1-2 years of age after many months of stimulation required to evoke $90-150$ class $V$ seizures).

\section{Immunohistochemistry for cholecystokinin, parvalbumin, and the neuronal GABA transporter}

At a minimum of $24 \mathrm{hr}$ after the last evoked seizure, the rats were anesthetized with chloral hydrate and perfused with a freshly prepared solution of $4 \%$ paraformaldehyde. The fixed brains were stored overnight in cold fixative, cryoprotected in a saturated solution of sucrose in fixative for a minimum of $24 \mathrm{hr}$, and sectioned horizontally with a microtome at a thickness of $60 \mu \mathrm{m}$. The sections were washed in PBS, $0.3 \%$ Triton $\mathrm{X}-100$, and $2 \%$ bovine serum albumin (BSA) for $20 \mathrm{~min}$, followed by a 45 min incubation in this mixture with $20 \%$ normal serum added. The sections were then incubated overnight in a mixture of $1 \%$ normal goat serum with primary anti-mouse antibodies specific for parvalbumin (PV; concentration, 1:10,000; Sigma, St. Louis, MO), primary anti-rabbit antibodies specific for cholecystokinin (concentration, 1:10,000; Sigma), and the neuronal GABA transporter GAT-1 (concentration, 1:1000; Chemicon, Temecula, CA). After incubation, the sections were washed briefly; washed twice for 15 min in PBS, $0.3 \%$ Triton X-100, and 2\% BSA; and then reacted for $3 \mathrm{hr}$ with biotinylated anti-mouse or anti-rabbit IgG in goat serum, followed by multiple washes in PBS, $0.3 \%$ Triton X-100, and 2\% BSA and reaction for $1 \mathrm{hr}$ in $\mathrm{ABC}$ reagent (Vector Laboratories, Burlingame, CA). The sections were again washed in PBS for $25 \mathrm{~min}$. The chromogen reaction was $5-10 \mathrm{~min}$ in diaminobenzidine $(0.04 \%$ in $0.01 \% \mathrm{H}_{2} \mathrm{O}_{2}$ to reduce endogenous peroxide activity), followed by washes in PBS. Reaction product was intensified in some of the sections by treatment with $1.4 \% \mathrm{AgNO}_{3}$ for $1 \mathrm{hr}$ at $56^{\circ} \mathrm{C}$, followed by washing in distilled $\mathrm{H}_{2} \mathrm{O}$, fixing in $5 \% \mathrm{Na}_{2} \mathrm{~S}_{2} \mathrm{O}_{3}$ for $10 \mathrm{~min}$, and washing in distilled $\mathrm{H}_{2} \mathrm{O}$. The sections were then treated briefly with $0.2 \% \mathrm{HAuCl}_{4}$, and final washes were performed before mounting, dehydration, and coverslipping. All sections from kindled and control rats were batch-processed to ensure identical reaction conditions.

Counting of CCK-labeled neurons. CCK-labeled interneurons in the dentate gyrus are typically located along the subgranular region near the border of the granule cell layer and the hilus, and are also scattered throughout the hilus. Preliminary experiments provided evidence that interneurons labeled by CCK were reduced in the dentate gyrus of kindled rats that experienced spontaneous seizures. Thus, a stereological evaluation was performed to provide a quantitative estimate of possible differences in the number of CCK-labeled interneurons in kindled rats compared with age-matched normal controls. After the rats were killed, perfused, and fixated overnight as described previously, the hippocampi were removed from this subset of rats, extended longitudinally along the septotemporal hippocampal axis, and sectioned transversely (i.e., orthagonal to the septotemporal axis, saving every section along the entire septotemporal length of the hippocampus). These sections from kindled and control rats were batch-processed for immunoreactivity to CCK as described previously, with the exception that intensification was not performed. Profile counts of all labeled cells with neuronal morphology were obtained by manual counting using a camera lucida in each section of a region including the entire granule cell layer and hilus. In sections at the most septal pole, the granule cell layer and hilus form an elliptical closed structure, and all labeled profiles were counted within this elliptical area. In the majority of sections in which the dentate gyrus forms a "U-shaped" structure opening into $\mathrm{CA} 3$, all labeled profiles were counted within the granule cell layer and hilus, as defined by borders extending from the tips of the granule cell to the tip of the extension of $\mathrm{CA}_{c}$ pyramidal neurons into the hilus.

The investigator who performed the counts was unaware of the identity of the sections, and the order of examination of the sections from control and kindled rats was randomized. Counts were obtained with a $4 \times$ objective ( 0.20 numerical aperture), and all labeled profiles with neuronal morphology that came into focus while moving the microscope headstage through the thickness of the section were manually counted. In each section, labeled neurons and their relative position in the section were recorded using a camera lucida and were summed to obtain the profile count per section through the thickness of the section. Previous studies have demonstrated that the measurement of section thickness or the $z$-axis in optical dissector methods is a critical influence in counting analyses (Guillery and August, 2002). The thickness ( $t$ ) of each section was determined by measuring the distance between the upper and lower focal planes of the section with the stage micrometer of the microscope using a $100 \times$ oil immersion objective. The stage micrometer was calibrated by the measurement of $10 \mu \mathrm{m}$ methylmethacrylate beads (Bangs Laboratories, Fishers, IN) that were mounted and coverslipped as for tissue sections to provide similar refractive conditions. The mean profile count $\left(N_{\mathrm{i}}\right)$ for each section was calculated and corrected for double counting of profiles cut at the surfaces of consecutive sections using the Abercromie formula: $N_{\mathrm{i}}=n_{\mathrm{i}} \times t /(t+d)$, where $N_{\mathrm{i}}$ is the corrected profile count, $n_{\mathrm{i}}$ is the uncorrected profile count in the section, $t$ is the section thickness, and $d$ is the average profile diameter (Konigsmark, 1969). For this analysis, there were no differences in the mean diameter of profiles in the control and kindled groups, and $d=14.1 \pm 0.2 \mu \mathrm{m}$. The mean section thickness was $17.1 \pm 0.1 \mu \mathrm{m}$. Corrected profile counts $\left(N_{\mathrm{i}}\right)$ were summed through the entire septotemporal length of the hippocampus and were also compared between kindled and control groups in bins defined by relative position of the consecutive sections along the length of the septotemporal axis corresponding to $0-25,25-50,50-75$, and $75-$ $100 \%$ of the full-length of the axis.

\section{Design considerations and statistical procedures}

All control and kindled groups were age-matched, and the age ranges of kindled and control groups always overlapped. Because the experiments were performed during a 4 year period in which unexpected drop-outs could not be avoided, individual rats were not paired by age or other variables. With the long duration of animal care required for planning and performing the experiments during this 4 year period, it was not possible to systematically blind laboratory personnel and investigators from the identity of the rats undergoing examination, except as noted. There were no systematic differences between unstimulated, electrode implanted, age-matched controls and unimplanted age-matched controls, so these groups were combined for analysis. Data are reported as mean \pm SEM. Group differences were evaluated for statistical significance by ANOVA or Student's $t$ test. When data were not distributed normally, analyses were performed using a nonparametric ANOVA by ranks (Kruskal-Wallis one-way, or Friedman two-way) or the MannWhitney rank sum test. When multiple comparisons were required, oneway ANOVA followed by Dunnett's test or the Newman-Keuls test were used post hoc for paired comparisons. Inferences on proportions were assessed by the $\chi^{2}$ test.

\section{Results}

\section{Development of spontaneous seizures in kindled rats}

The physiological and anatomical experiments in this study were conducted in $>96$ kindled rats that experienced a range of $1 \mathrm{AD}$ to $>200$ class $\mathrm{V}$ evoked seizures, and 82 age-matched controls. Preliminary behavioral observations revealed that spontaneous seizures were frequently observed during routine handling in kindled rats after $\sim 90$ class V seizures evoked by kindling stimulation. To further define the stage at which spontaneous seizures emerge in rats undergoing repeated kindling stimulation, 27 kindled rats with $>90$ evoked class $V$ seizures were systematically observed for spontaneous seizures during $8 \mathrm{hr}$ of daily behavioral monitoring and were compared with a group of age-matched unstimulated controls, including a subset of control rats with implanted electrodes that never received kindling stimulation. During this systematic monitoring, spontaneous seizures were observed in 11 of 27 kindled rats with $>90$ evoked class V sei- 
Table 1. Summary of kindling and control groups studied by paired-pulse and single-electrode voltage-clamp methods

\begin{tabular}{|c|c|c|c|c|}
\hline & \multicolumn{2}{|c|}{ Kindled } & \multicolumn{2}{|c|}{ Age-matched controls } \\
\hline & Rats & $\begin{array}{l}\text { Hippocampal } \\
\text { slices }\end{array}$ & Rats & $\begin{array}{l}\text { Hippocampal } \\
\text { slices }\end{array}$ \\
\hline $3 \mathrm{ADs}$ & 3 & 14 & 6 & 10 \\
\hline 3 Class V & 18 & 42 & 25 & 55 \\
\hline 35 Class V & 9 & 16 & 15 & 26 \\
\hline$>90$ Class V & 14 & 26 & 14 & 30 \\
\hline$>100$ Class V plus spontaneous seizures & 5 & 9 & 5 & 8 \\
\hline
\end{tabular}

zures, but no spontaneous seizures were observed in the control group of age-matched normal rats $\left(\chi^{2} ; p<0.001\right)$. Spontaneous seizures were not observed in kindled rats with $<90$ class $\mathrm{V}$ evoked seizures.

In a subset of kindled rats with $\geq 100$ evoked class V seizures evoked by olfactory bulb stimulation, additional systematic behavioral monitoring to a criterion of three spontaneous seizures revealed that the first observed spontaneous seizure was reliably followed by recurring spontaneous seizures ( $n=6$ of 6 rats) that confirmed that kindled rats with $>90-100$ class $\mathrm{V}$ seizures are likely to experience recurring unprovoked spontaneous seizures. Spontaneous seizures were observed after $>90-100$ class V seizures evoked by kindling of the olfactory bulb or the perforant path, and therefore did not appear to be related to the site of kindling stimulation.

\section{Evolving alterations in paired-pulse inhibition in the dentate gyrus of kindled rats}

It was of interest to consider whether the emergence of spontaneous seizures in kindled rats was caused by seizure-induced alterations in inhibition. As a preliminary assessment of the state of inhibition in kindled rats experiencing spontaneous seizures, paired-pulse measurements were performed in hippocampal slices from rats at various stages of kindling, including after 90 class V seizures when spontaneous seizures begin to emerge, and were compared with recordings from age-matched controls (see Table 1 for a summary of kindled and agematched control rats studied by pairedpulse and single-electrode voltage-clamp methods).

In the paired-pulse method, stimulation of the perforant path with a $50 \mu \mathrm{sec}$ square wave stimulus evokes a population EPSP accompanied by a population spike (PS), which is a measure of the number and synchrony of granule cell action potentials. When stimuli are delivered in pairs at interpulse intervals of 15-25 msec, previous studies have demonstrated that in the normal dentate gyrus, the ratio of the amplitude of the second PS to the first is $<1$, which indicates reduced granule discharge in response to the second pulse of the pair. This reduction in amplitude of the second PS has been referred to as pairedpulse inhibition and has been demonstrated to be a measure of the strength of GABAergic inhibition (Tuff et al., 1983b; Oliver and Miller, 1985) (Fig. $1 A$ ). In agreement with previous studies of paired-pulse responses in kindled rats (Tuff et al., 1983b; Oliver and Miller, 1985; de Jonge and Racine, 1987; Stringer and Lothman, 1989), field potentials evoked in the dentate gyrus by paired stimulation of the perforant path at an interpulse interval of 15 msec in hippocampal slices from kindled rats demonstrated an increase in paired-pulse inhibition, as measured by reduction in the amplitude of the second PS compared with the first (Fig. 1, compare $A, B, E)$. The increase in paired-pulse inhibition at these interpulse intervals was observed at 1 week after as few as three class V seizures ( $n=42$ hippocampal slices from eight rats) and was also observed in hippocampal slices from kindled rats at 1 week after the last of 35 class $\mathrm{V}$ seizures $(n=16$ slices from nine
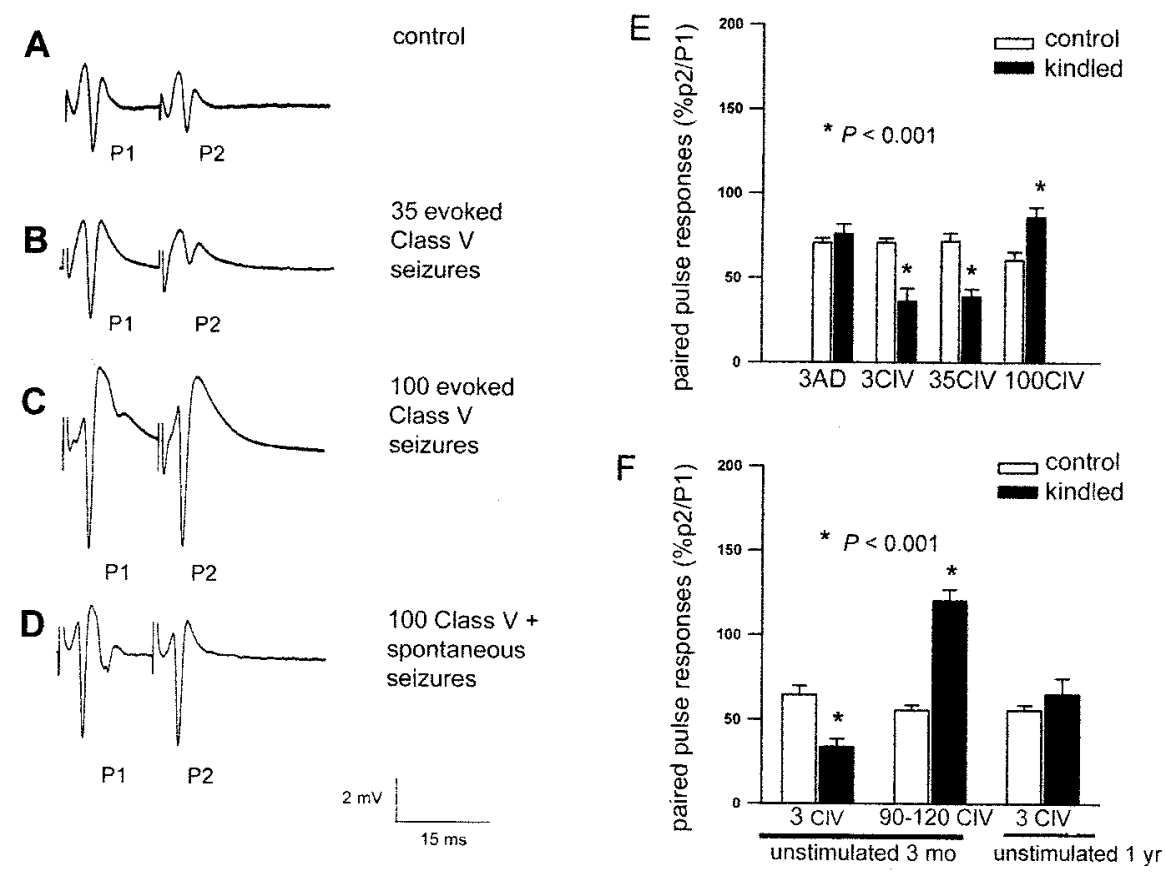

Figure 1. Evolving alterations in paired-pulse responses in the dentate gyrus of kindled rats as a function of the number of evoked seizures. A, Extracellular field potentials evoked in the dentate gyrus by paired stimuli delivered to fibers of the perforant path at an interpulse pulse interval of 15 msec using the lowest stimulus intensity that evoked a maximal response, as determined by input- output curves. Paired-pulse inhibition is indicated by the reduction in amplitude of the population spike of the second response $(P 2)$ compared with the first $(P 1)$. Paired-pulse inhibition is present when the ratio $P 2: P 1$ is $<1$. $B$, In the dentate gyrus from a kindled rat that experienced 35 evoked class $V$ seizures, paired-pulse inhibition was increased compared with the agematched control in A, as demonstrated by the reduction of the ratio of P2:P1. C, In a kindled rat that experienced 100 evoked class $V$ seizures, there was a reduction of paired-pulse inhibition, as demonstrated by the increase in the ratio of the amplitude of the population spike of the second response (P2) compared with the amplitude of the first population spike (P1).D, In a kindled rat with $>100$ class V seizures that was also observed to have spontaneous seizures, paired-pulse inhibition was also reduced, as indicated by the increase in the amplitude of the population spike of the second response (P2) compared with the amplitude of the first population spike (P1).E, Evolving alterations in paired-pulse inhibition in the dentate gyrus as a function of the number of evoked seizures. The ratio of the amplitude of the second population spike to the amplitude of first population spike (P2:P1) is expressed as a percentage for kindled rats that experienced a range of three evoked ADs to 100 evoked class V (CIV)seizures ( filled bars) compared with age-matched controls (open bars). Paired-pulse inhibition is present when the ratio of P2:P1 is $<100 \%$. Pairedpulse inhibition was unchanged after three ADs but increased after 3 or 35 class V seizures, as indicated by a reduction in the ratio P2:P1 compared with controls. Paired-pulse inhibition was reduced compared with age-matched controls after 100 evoked class V seizures, as indicated by an increase in the ratio of P2:P1 compared with age-matched controls. There were no significant differences between kindled rats that received olfactory bulb or perforant-path stimulation. Asterisks indicate significant differences between kindled and age-matched control groups. $F$, The increase in paired-pulse inhibition was observed at 3 months after the last of three evoked class V seizures but was not observed at 1 year after the last of three evoked class V seizures. In hippocampal slices from kindled rats examined at 3 months after the last of $90-100$ evoked class $V$ seizures, there was not only a reduction but also a loss of paired-pulse inhibition as indicated by a ratio of $\mathrm{P} 2: \mathrm{P} 1>100 \%$. 

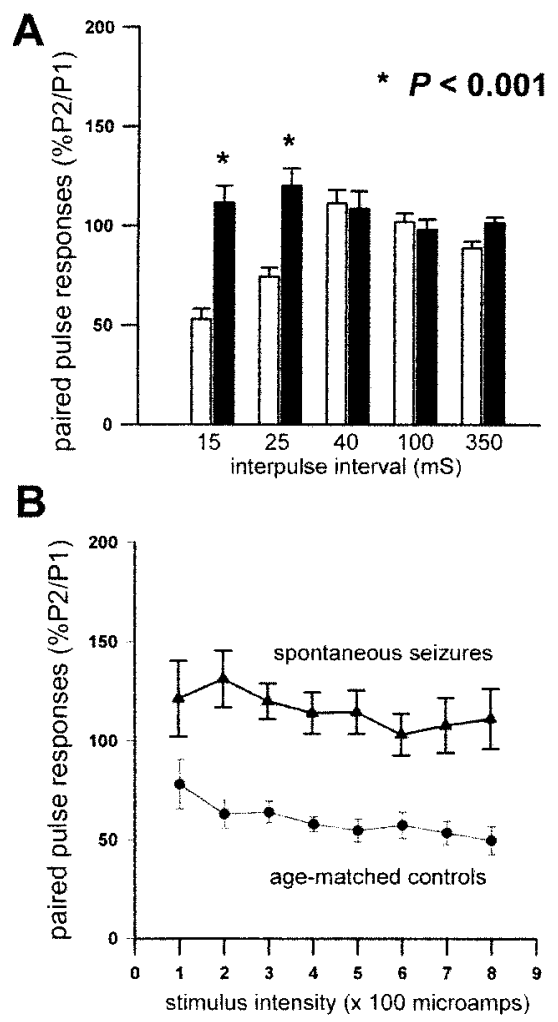

Figure 2. Loss of paired-pulse inhibition in kindled rats experiencing spontaneous seizures. $A$, In kindled rats with $>100$ evoked class $V$ seizures that were experiencing spontaneous seizures as determined by behavioral monitoring, paired-pulse inhibition was lost at interpulse intervals of 15 and $25 \mathrm{msec}$, as indicated by ratios of P2:P1 > 100\% compared with agematched controls that demonstrated normal paired-pulse inhibition (P2:P1 $<100 \%)$. There were no significant differences in paired-pulse responses at interstimulus intervals of 40,100 , or $350 \mathrm{msec}$. Asterisks indicate significant differences between kindled rats with spontaneous seizures (filled bars) and age-matched controls (open bars). B, The loss of paired-pulse inhibition (P2:P1 > 100\%) was observed at 15 msec interpulse intervals across a range of stimulus intensities. Triangles, Spontaneous seizures; circles, age-matched controls.

rats), but was not observed in slices from kindled rats that experienced only three $\mathrm{ADs}$ ( $n=14$ slices from three rats) (Fig. $1 B, E$ ).

In contrast, at 1 week after the last of $\geq 90$ class $V$ seizures, there was a reduction or loss of paired-pulse inhibition $(n=26$ slices from 14 rats) (Fig. $1 C-E$ ). In a subset of kindled rats that experienced $>100$ evoked class V seizures and were observed by behavioral monitoring to have experienced at least three unprovoked spontaneous class $\mathrm{V}$ seizures, paired-pulse inhibition was lost ( $n=9$ slices from five rats) (Fig. $1 D, E$ ). The reduction of paired-pulse inhibition was also observed at 3 months after the last of $90-120$ class $\mathrm{V}$ seizures ( $n=10$ slices from six rats) (Fig. $1 F)$, which suggested that the loss of paired-pulse inhibition was long-lasting and possibly permanent. The increase in pairedpulse inhibition after three class V seizures was not observed in a subset of kindled rats at 1 year after the last evoked seizure $(n=13$ slices from four rats) (Fig. $1 F$ ), suggesting that the seizureinduced increase in inhibition at early stages of kindling may not be permanent.

The loss of paired-pulse inhibition in kindled rats with $\geq 90$ evoked kindled seizures was observed at interpulse intervals of 15-25 msec, which is consistent with a reduction in $\mathrm{Cl}^{-}$dependent GABAergic inhibition (Oliver and Miller, 1985). No changes in paired-pulse relationships were observed at interpulse intervals of 40, 100, or $350 \mathrm{msec}$ (Fig. 2A). The loss of pairedpulse inhibition in kindled rats with $\geq 90$ evoked seizures was observed across a range of stimulus intensities (Fig. $2 B$ ) and in kindled rats that received olfactory bulb or perforant-path stimulation.

\section{Alterations in the kinetics of evoked IPSCs in kindled rats with spontaneous seizures}

A variety of alterations in synaptic transmission could contribute to the alterations observed in paired-pulse relationships. In addition to loss of GABAergic inhibition, increases in excitatory processes or a combination of increased excitation and reduced inhibition could produce a reduction or loss of paired-pulse inhibition. Although the loss of paired-pulse inhibition at interpulse intervals of 15-25 msec is consistent with the reduction in GABAergic inhibition (Tuff et al., 1983b; Oliver and Miller, 1985), more direct measures of inhibition are necessary to determine whether the observed loss of paired-pulse inhibition was caused by seizure-induced reduction of GABAergic synaptic inhibition. To address these possibilities, single-electrode voltageclamp recordings were performed in eight granule cells recorded in hippocampal slices from a subset of five kindled rats with $>100$ class $\mathrm{V}$ seizures evoked by stimulation of the olfactory bulb that also experienced at least three recurrent spontaneous seizures confirmed by behavioral monitoring, and were compared with recordings in 10 granule cells from five age-matched, unstimulated olfactory bulb-implanted controls. The IPSC was evoked in granule cells by direct stimulation of inhibitory interneurons during bath application of $20 \mu \mathrm{M}$ DNQX and $50 \mu \mathrm{M}$ APV to block EPSCs, and was measured across a range of holding potentials in hippocampal slices from the kindled and age-matched control rats (Fig. 3A).

There were no significant differences in the average resting membrane potential, reversal potential of the evoked IPSC, and median stimulus intensity for the kindled and age-matched control rats studied by single-electrode voltage-clamp methods ( $\mathrm{Ta}$ ble 2) that supported the validity of comparisons of IPSC kinetics between these groups. However, there were consistent alterations in the amplitude and kinetics of the evoked IPSC (Fig. 3B-E), including significant reductions of amplitude and charge transfer of IPSCs evoked by a stimulus pulse of standardized intensity determined from input-output curves (Fig. $3 C$ ). The duration of the IPSC was shortened, as demonstrated by a reduction in the $10-90 \%$ decay time and the decay time constant $\tau$ (Fig. 3D,E). These measurements confirmed that the reduction of GABAergic synaptic currents contributed to the loss of paired-pulse inhibition in epileptic kindled rats experiencing spontaneous seizures.

\section{Seizure-induced alterations in subclasses of GABAergic interneurons}

The loss of paired-pulse inhibition and reduction of GABAergic evoked IPSCs in kindled rats experiencing spontaneous seizures may be caused by a variety of seizure-induced cellular alterations, including reductions of afferent input to interneurons, loss of GABAergic inhibitory interneurons, reduced GABA release from interneurons, alterations in GABAergic receptor subunits, or combinations of alterations. GABAergic interneurons can be subclassified on the basis of peptide expression and morphology into distinct subclasses that may play specific functional roles in neural circuitry (Freund and Buzsaki, 1996; Miles et al., 1996). Diverse interneuron subtypes give rise to feedforward and feedback inhibitory circuits and participate in the regulation of transmitter release, dendritic processing and integration of synaptic inputs, and spike generation that shape response properties of single neurons, oscillations in neural networks, synaptic plastic- 
ity, and epileptic synchronization (Freund and Buzsaki, 1996). For example, subclasses of interneurons identified by immunostaining with parvalbumin, CCK, and GAT-1 provide axo-somatic and axo-axonic inhibitory synaptic terminals on principal cells (Leranth and Frotscher, 1986; Halasy and Somogyi, 1993; Ribak et al., 1993, 1996; Freund and Buzsaki, 1996) and are therefore potentially critical for control of spike generation from the spike initiation zone in axon initial segments and neuronal output to synaptic targets. As a preliminary step to characterize the possible underlying cellular alterations associated with the loss of paired-pulse inhibition and reduction of GABAergic IPSCs accompanying the development of spontaneous seizures in kindled rats, alterations in subclasses of interneurons identified by parvalbumin, calbindin, calretinin, vasoactive intestinal peptide, neuropeptide $\mathrm{Y}$, somatostatin, nitric oxide synthetase, CCK, and GAT-1 were examined in pilot studies. In these pilot studies, serial sections were reacted with subclass-specific antibodies. Significant alterations were apparent only in the GAT-1 and CCK subclasses in kindled rats experiencing spontaneous seizures and were therefore examined in further detail.

In normal rats and age-matched controls, GAT-1 immunoreactivity was observed throughout the neuropil and was particularly prominent in the granule cell layer bordering the subgranular region of the hilus, which is the site of axon initial segments arising from granule cells and projecting into the hilus in the direction of CA3 (Fig. 4A). There was a prominent reduction of GAT-1 immunoreactivity in the dentate gyrus and hippocampus of kindled rats that experienced $>90$ evoked seizures $(n=5$ of 5 rats) (Fig. 4C). Spontaneous seizures were observed in three rats from this group. In this region of kindled rats with $>90$ class $\mathrm{V}$ evoked seizures and spontaneous seizures, there was little or no immunoreactivity compared with age-matched controls. GAT-1 immunoreactivity appeared normal at earlier stages of kindling ( $n=4$ of 4 kindled rats after three class $\mathrm{V}$ seizures). In four of six kindled rats that experienced $76-80$ class $V$ seizures, the stage just before the onset of spontaneous seizures, GAT-1 immunoreactivity appeared normal in the dentate gyrus (Fig. $4 B$ ) but was reduced in two of six rats from this group. The differences between rats with $\geq 90$ evoked class $\mathrm{V}$ seizures and spontaneous seizures were significant compared with controls (Fishers exact test; $p=0.00216)$ and all other groups $\left(\chi^{2}=15.4\right.$; $\mathrm{df}=3 ; p=$ $0.0015)$, which supports the idea that seizure-induced loss of GAT-1 immunoreactivity was associated with the emergence of spontaneous seizures.

CCK-labeled interneurons are typically located along the subgranular region near the border of the granule cell layer and the hilus and are occasionally found deeper in the hilus (Fig. 4D). In addition to the densely labeled interneurons in the hilus, fine punctate granules labeled by CCK were scattered throughout the hilus and granule cell layer in normal rats (Fig. $4 D$ ). In five of five kindled rats that experienced $>90$ evoked seizures, there appeared to be a reduction of CCK-labeled interneurons and
B amplitude of IPSC (nA)

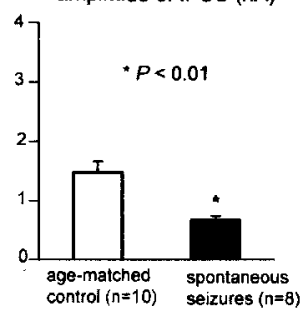
$10-90 \%$ decay time $(\mathrm{ms})$
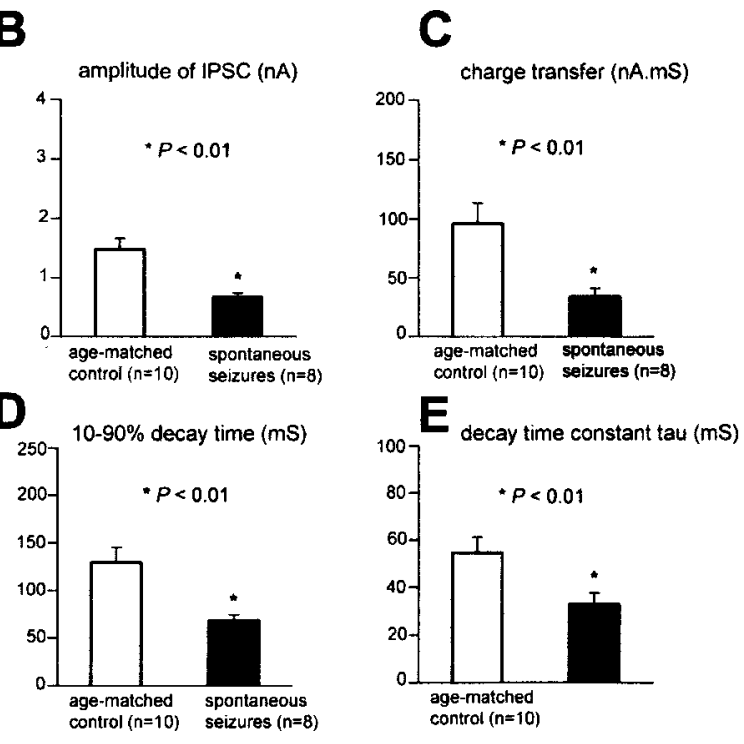

pontaneous

seizures

control

spontaneous seizures

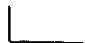

Figure 3. Reduction of GABAergic inhibition in granule cells of the dentate gyrus in kindled rats experiencing spontaneous seizures. $A$, In a hippocampal slice from a kindled rat with $>100$ evoked class V seizures that was experiencing spontaneous ures as determined by behavioral monitoring, there was a reduction of the amplitude and duration of the evoked monosynaptic output curves (see Materials and Methods for details). For comparisons between the kindled and age-matched control groups, asterisks indicate significant differences. $n$ refers to the number of granule cells recorded in each group.

Table 2. Intrinsic, synaptic, and stimulus properties of granule cells in kindled rats with spontaneous seizures and age-matched controls

\begin{tabular}{lllc}
\hline & $\begin{array}{l}100 \text { Class V } \\
\text { plus spontaneous } \\
\text { seizures }\end{array}$ & $\begin{array}{l}\text { Age-matched } \\
\text { controls }\end{array}$ & \\
\hline $\begin{array}{l}\text { Resting membrane potential } \\
(\mathrm{mV})\end{array}$ & $-76.1 \pm 1.8$ & $-72.7 \pm 1.5$ & $\begin{array}{c}p=0.16, \mathrm{NS} \\
(t \text { test })\end{array}$ \\
$\begin{array}{l}\text { IPSC reversal potential } \\
(\mathrm{mV})\end{array}$ & $-66.1 \pm 1.4$ & $-65.7 \pm 0.9$ & $\begin{array}{c}p=0.8, \mathrm{NS} \\
(t \text { test })\end{array}$ \\
$\begin{array}{l}\text { Median stimulus intensity }(\mu \mathrm{A}) \\
\text { (n) }\end{array}$ & 525 & 475 & $\begin{array}{c}p=0.23, \mathrm{NS} \\
\text { (rank sum test) }\end{array}$ \\
\hline
\end{tabular}

punctate-staining observed in the hilus and granule cell layer when compared with age-matched normal controls ( $n=7$ rats) (Fig. 4, compare $E, F$ ). The population of CCK-labeled neurons and the pattern of punctate labeling appeared relatively normal in kindled rats with $<90$ evoked seizures ( $n=11$ rats) (Fig. $4 D, E$ ).

To further evaluate the extent of seizure-induced loss of the CCK subclass of interneurons, stereological counting methods were used to quantify the number of CCK-immunoreactive interneurons in kindled rats with 3, 60-80, or $>90$ evoked class $\mathrm{V}$ seizures, and in controls age-matched to the group with $>90$ class $\mathrm{V}$ seizures. There was an overall $\sim 33 \%$ reduction of CCKimmunoreactive interneurons in kindled rats with $>90$ class $\mathrm{V}$ seizures ( $n=4$ rats) compared with controls age-matched to the group with $>90$ seizures $(n=4)$, and kindled rats with 3 or $60-80$ evoked class $\mathrm{V}$ seizures $(n=9$ rats; $p<0.03$; ANOVA) (Fig. 5A). The reduction of CCK-immunoreactive interneurons in rats with $>90$ evoked seizures compared with age-matched controls indicates that aging effects cannot account for the neuronal loss, but an interaction of aging and seizures cannot be excluded. There was a significant reduction of CCK-immunoreactive inter- 

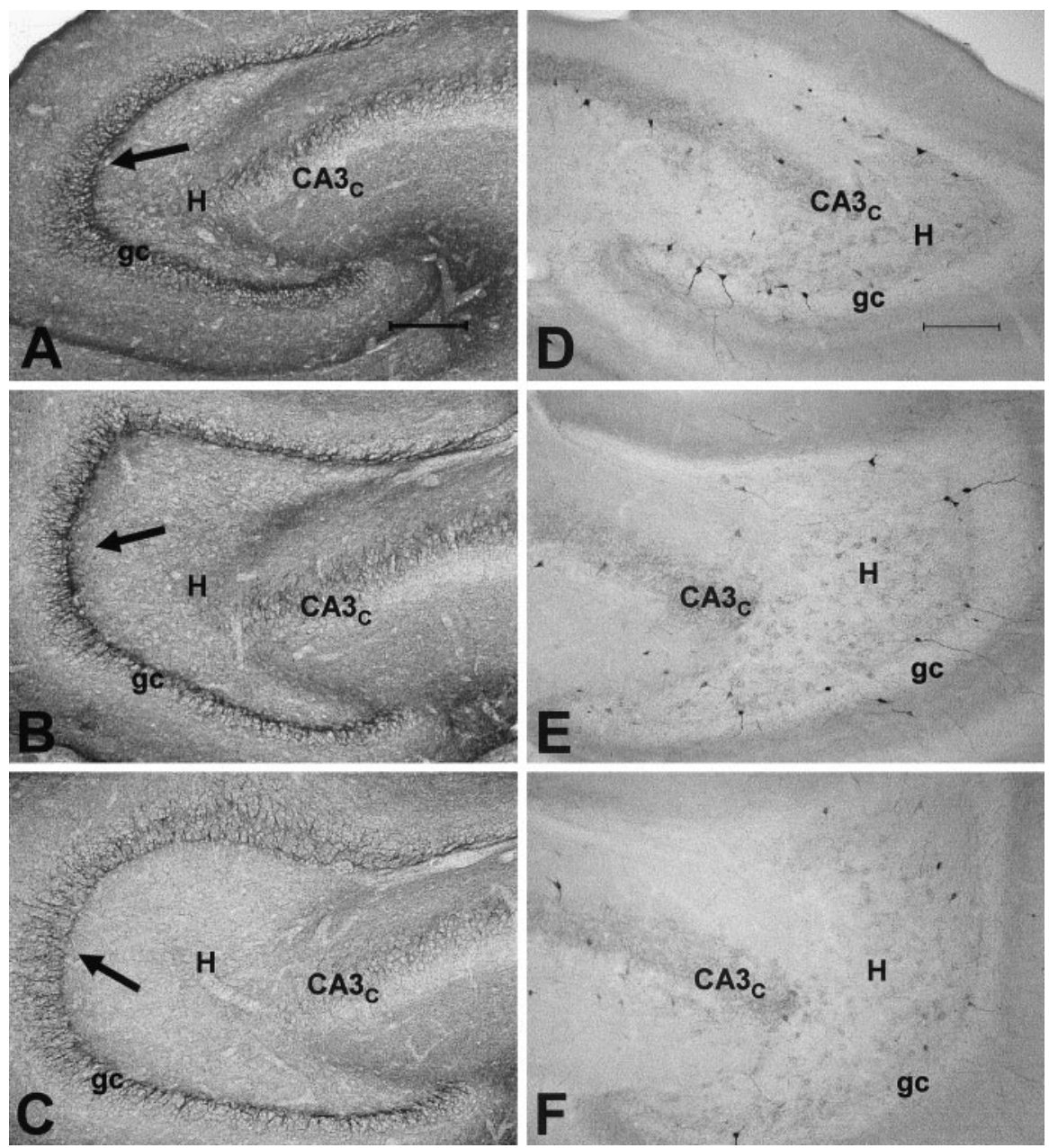

Figure 4. Seizure-induced reduction of GAT-1 and CCK immunoreactivity in the dentate gyrus of kindled rats experiencing spontaneous seizures. Immunoreactivity was intensified in these sections by silver treatment, as described in Materials and Methods, and all sections were batch processed. $A$, In normal rats, GAT- 1 immunoreactivity is observed throughout the neuropil, but is particularly prominent in the granule cell layer $(g c)$ bordering the subgranular region of the hilus ( $H$; arrows), which is the site of axon initial segments arising from granule cells and projecting into the hilus toward $C A{ }_{C} \cdot B$, In a kindled rat that experienced 76 class $V$ seizures, which is a stage just before the onset of spontaneous seizures, GAT-1 immunoreactivity appeared normal in the dentate gyrus. C, In a kindled rat that experienced 209 evoked class V seizures, immunoreactivity was reduced in comparison with normal or age-matched controls. The loss of GAT-1 immunoreactivity was particularly prominent along the border of the granule cell layer and subgranular region of the hilus, which is the site of axon initial segments and spike initiation. $D$, In a nearby section

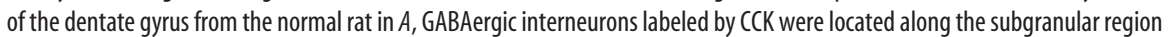
near the border of the granule cell layer and the hilus and were occasionally also observed deeper in the hilus. Fine punctate granules labeled by CCK were also typically scattered throughout the hilus and granule cell layer in normal rats. $E$, In the same kindled rats that experienced 76 class $V$ seizures, the distribution and number of CCK-labeled interneurons and punctate granular staining appeared normal. $F$, In the same kindled rat shown in C that experienced 209 evoked class $V$ seizures, there was a reduction of interneurons labeled by CCK and in the punctate staining observed in the hilus and granule cell layer. Scale bar, $200 \mu \mathrm{m}$.

neurons in the $>90$ class $\mathrm{V}$ group compared with kindled rats with 60-80 evoked class V seizures $(p=0.0004)$, indicating an association of seizure-induced loss of CCK-immunoreactive interneurons with the emergence of spontaneous seizures. A reduction of the number of CCK-labeled neurons in the dentate gyrus of kindled rats with $>90$ evoked class $\mathrm{V}$ seizures was observed along the entire septotemporal axis of the hippocampal formation $(p<0.03)$, except for a nonsignificant trend to reduction at the septal (rostral) pole (Fig. $5 B$ ).

\section{Discussion}

These physiological and anatomical experiments identified functional and cellular alterations in the hippocampus associated with the emergence of spontaneous seizures. Spontaneous seizures were observed in 11 of 27 rats after $\sim 90-100$ repeated brief seizures evoked by kindling of either the olfactory bulb or perforant path, and were the long-term functional outcome of repeated episodes of evoked synchronous neural activity. The sequence of progressive seizure-induced molecular and cellular alterations underlying the emergence of spontaneous seizures is an example of long-term activity-dependent plasticity in neural circuits and has potential relevance for the common disorder of epilepsy in which seizure-induced cellular alterations may contribute to dysfunction.

Predictable emergence of spontaneous seizures in kindled rats after $\sim 90-100$ evoked seizures

There is limited insight about cellular alterations accompanying the emergence of spontaneous seizures after repeated brief evoked seizures in rats and primates (Wada et al., 1975; Pinel and Rovner, 1978). It is uncertain whether spontaneous seizures occur reliably and predictably after a specific number of evoked seizures or merely sporadically in the advanced kindled state. Behavioral monitoring revealed that spontaneous seizures were observed after $\sim 90-100$ class $\mathrm{V}$ seizures evoked by either olfactory bulb or perforant-path stimulation. Additional spontaneous seizures were observed after the initial spontaneous seizure, confirming that kindled animals with spontaneous seizures were epileptic, as defined by recurring spontaneous seizures.

The observation of spontaneous seizures after $\sim 90-100$ evoked class V seizures should not be regarded as a precise latency to spontaneous seizures but rather as a period of transition to a state with increased probability of spontaneous episodes of synchronous neural activity and seizures (Hellier et al., 1998; Pitkänen et al., 2002). The stage of $\sim 90-100$ evoked class $\mathrm{V}$ seizures was recognized retrospectively as a period of transition to increased probability of spontaneous seizures and does not imply that all kindled rats experience spontaneous seizures after 90-100 evoked class V seizures, but merely that spontaneous seizures become increasingly likely as indicated by their recognition in $\sim 40 \%$ of rats with $90-100$ evoked class $\mathrm{V}$ seizures undergoing $8 \mathrm{hr}$ of behavioral monitoring per day. This is probably a low estimate limited by the sampling methods; more sensitive continuous video-EEG-recording methods might detect additional rats with spontaneous seizures after 90-100 evoked class V seizures, and might also reveal that occasional spontaneous seizures occur in kindled rats with $<90$ evoked seizures. Although both status epilepticus and repeated brief seizures eventually induce spontaneous seizures, the gradual induction of spontaneous seizures in the absence of extensive damage permitted detailed analysis of 
specific structural and functional alterations associated with this transition.

\section{Emergence of spontaneous seizures is associated with seizure-induced reduction of $\mathrm{GABA}_{\mathrm{A}}$ inhibition}

This study confirmed that repeated seizures increase paired-pulse inhibition and other measures of inhibition during early stages of kindling (Tuff et al., 1983a,b; Oliver and Miller, 1985; Shin et al., 1985; de Jonge and Racine, 1987; Stringer and Lothman, 1989; Otis et al., 1994; Buhl et al., 1996; Nusser et al., 1998). Paired-pulse inhibition increased after three class $\mathrm{V}$ seizures but not after only a few ADs with partial seizures (class I-III), which implies that more than three partial seizures or secondary generalized seizures may be required.

The initial increase was not permanent, because paired-pulse inhibition was reduced or lost in the dentate gyrus after 90-100 class V seizures evoked by olfactory bulb or perforant-path stimulation, and importantly, was consistently lost in all rats with spontaneous seizures revealed by behavioral monitoring. The loss of paired-pulse inhibition was long-lasting and probably permanent. Because rats with $>90-100$ class $\mathrm{V}$ seizures might have spontaneous seizures that were undetected by the limited observation methods, spontaneous seizures may not induce an acute increase in paired-pulse inhibition as observed during early stages of kindling.

Loss of paired-pulse inhibition associated with spontaneous seizures could be caused by increases in glutamatergic excitatory processes, loss of GABAergic inhibition, or a combination of increased excitation and reduced inhibition. Loss of paired-pulse inhibition at interpulse intervals of $15-25 \mathrm{msec}$ corresponding to the time course of $\mathrm{GABA}_{\mathrm{A}}$-dependent $\mathrm{Cl}^{-}$conductance is consistent with a seizure-induced alteration in $\mathrm{GABA}_{\mathrm{A}}$ inhibition (Tuff et al., 1983b; Oliver and Miller, 1985) that was confirmed by the reduced amplitude and shortened duration of evoked IPSCs recorded by single-electrode voltage-clamp methods. Mechanisms underlying the altered kinetics of the evoked IPSCs were not specifically addressed in these experiments but could include loss of GABAergic terminals; alterations in the number, subunit composition, or biophysical properties of GABA receptors; or a variety of mechanisms.

\section{Progressive seizure-induced alterations leading to spontaneous seizures}

Repeated evoked seizures induce a variety of cellular and molecular alterations in the dentate gyrus and other regions, including neuronal apoptosis and cumulative neuronal loss resembling hippocampal sclerosis, neurogenesis, mossy fiber sprouting, gliosis, and reorganization of receptors and other proteins (Sutula et al., 1988, 1998; Represa et al., 1989; Cavazos and Sutula, 1990; Cavazos et al., 1991, 1994; Bengzon et al., 1997; Pretel and Piekut, 1997; Adams et al., 1998; Dalby et al., 1998; Parent et al., 1998; Kotloski et al., 2002). Cumulative seizure-induced alterations could potentially alter the balance of excitation and/or inhibition and modify functional properties of hippocampal circuits contributing to the emergence of spontaneous seizures.

Because repeated brief kindled seizures induce cumulative neuronal loss (Cavazos and Sutula, 1990; Cavazos et al., 1994; Bengzon et al., 1997; Pretel and Piekut, 1997; Dalby et al., 1998; Dalby and Mody, 2001; Kotloski et al., 2002), it was of interest to investigate whether seizure-induced loss of GABAergic interneurons contributed to the alterations in the kinetics of $\mathrm{GABA}_{\mathrm{A}}$ dependent IPSCs accompanying spontaneous seizures. In pilot studies, expression of CCK and GAT-1, which label GABAergic interneuron subclasses providing axo-somatic and axo-axonic inhibitory inputs to granule cells (Leranth and Frotscher, 1986; Freund and Buzsaki, 1996; Ribak et al., 1996), was reduced in kindled rats with loss of paired-pulse inhibition and spontaneous seizures. Markers for other subclasses, including the parvalbumin subclass that also provides axo-axonic and axo-somatic inhibition (Ribak et al., 1993; Freund and Buzsaki, 1996), were examined in serial sections in pilot studies but did not appear to be significantly altered.

CCK and GAT-1 immunoreactivity appeared normal in kindled rats after 80 class $\mathrm{V}$ evoked seizures but was consistently reduced after 90 class $\mathrm{V}$ seizures. The reduction of CCK and GAT-1 immunoreactivity in association with the emergence of spontaneous seizures suggests that seizure-induced reduction of these subclasses and loss of axo-somatic and axo-axonic inhibition may contribute to spontaneous seizures. Loss of GAT-1 immunoreactivity was particularly prominent in the infragranular region of the granule cell layer (the site of axon initial segments) but was observed throughout the hippocampus. Loss of CCKlabeled interneurons, as measured by counting methods, occurred along the entire septotemporal axis of the hippocampus. Because the reduction of CCK and GAT-1 immunoreactivity was not observed in age-matched controls, aging alone cannot ac- 
count for the reductions, but an interaction of the cumulative effects of repeated seizures with aging cannot be excluded.

Loss of these markers could be caused by reduced expression rather than loss of the interneuron populations, but this seems unlikely given ongoing, progressive neuronal loss in kindled rats and the accompanying loss of inhibition detected by physiological methods. If expression of the GABA transporter GAT-1 was reduced without interneuron loss, there would be an increase in inhibition as a consequence of reduced reuptake of synaptically released GABA, but this was not observed. Counting methods supported the interpretation that the reduction of CCK immunoreactivity was caused by neuronal loss; however, with technical limitations such as comparability of antibody penetration even in batch-processed sections, the counts should not be regarded as a precise measure of the absolute number of CCK interneurons.

\section{Seizure-induced loss of axo-axonic and axo-somatic inhibition and the development of spontaneous seizures}

The CCK and GAT-1 interneuron subclasses in the dentate gyrus have morphological features of basket cells and chandelier cells and project axo-somatic and axo-axonic terminals forming symmetric GABAergic synapses (Gray type II) on principal cells (Leranth and Frotscher, 1986; Soriano et al., 1990; Halasy and Somogyi, 1993; Ribak et al., 1993, 1996). These features are especially suited for perisomatic and axon initial segment inhibition that potentially control timing and suppression of spikes generated by $\mathrm{Na}^{+}$channels that have a high density on axon initial segments (Buhl et al., 1994; Soltesz et al., 1995; Freund and Buzsaki, 1996). Seizure-induced loss of the CCK and GAT-1 subclasses in the dentate gyrus would reduce spike suppression (Buhl et al., 1994; Soltesz et al., 1995; Miles et al., 1996) and enhance propagation of spike output to CA3, thereby eroding "filtering" properties of the dentate gyrus and potentially increasing the susceptibility of hippocampal neural circuits to epileptic synchronization (Buhl et al., 1994; Soltesz et al., 1995; Freund and Buzsaki, 1996; Behr et al., 1998, 2001). Although the loss of axoaxonic and axo-somatic inhibition is a potentially attractive mechanism for neural synchronization and seizure-induced epileptogenesis, other cellular alterations are also likely to contribute to reduced inhibition and synchronized neuronal bursting. For example, seizure-induced changes in $\mathrm{GABA}_{\mathrm{A}}$ receptor subunits or alterations in biophysical properties of channels could shorten or reduce IPSCs (Stell and Mody, 2002). Seizure-induced increases in recurrent excitation as a result of excitatory circuits formed by sprouted mossy fibers may also contribute to the loss of paired-pulse inhibition (Wuarin and Dudek, 1996, 2001; Lynch and Sutula, 2000). Seizure-induced alterations in other hippocampal and limbic areas may also be important for epileptic synchronization (Gorter et al., 2002). These experiments provide evidence of an association among loss of inhibition, loss of subclasses of interneurons providing axo-somatic and axo-axonic inhibition, and emergence of spontaneous seizures. Additional experiments are necessary to define causality among these alterations, but it is likely that multifactorial and combinatorial processes contribute to the intermittent paroxysmal expression of neuronal synchronization during seizures.

\section{Implications for human epilepsy}

Reduction of GAT-1 immunoreactivity and loss of GABA transporter function have been reported in intractable human temporal lobe epilepsy (During et al., 1995; Mathern et al., 1999). Loss of GAT-1 has been observed in CA1 but is reported to increase in the inner molecular layer of the dentate gyrus after pilocarpine- induced status (Andre et al., 2001), suggesting that the effects of seizures may be region and model specific. Selective loss of PVimmunoreactive interneurons and terminals has been observed in surgically resected hippocampus in both humans and models of status epilepticus (Zhu et al., 1997; Gorter et al., 2001; Wittner et al., 2001) and is in contrast to the relative preservation of PV immunoreactivity in kindled rats with spontaneous seizures. The observation that seizure-induced loss of CCK and GAT-1 immunoreactivity occurs in the dentate gyrus at advanced stages of kindling in association with reduced inhibition and spontaneous seizures suggests that repeated seizures may play a role in the development of intractable human temporal lobe epilepsy.

The progressive alterations induced by repeated brief seizures in hippocampal circuitry have significant adverse consequences, including increased susceptibility to additional seizures (Goddard 1969; Goddard et al., 1969) and memory dysfunction (Sutula et al., 1995). The slowly evolving, seizure-induced reduction of inhibition supports the importance of achieving complete control of seizures in people with epilepsy. Molecular and genetic analysis of the evolving seizure-induced cellular and functional alterations may provide new targets for therapeutic intervention and the prevention of adverse consequences of poorly controlled epilepsy.

\section{References}

Adams B, Vonling E, Vaccarella L, Ivy GO, Fahnestock M, Racine RJ (1998) Time course for kindling-induced changes in the hilar area of the dentate gyrus-reactive gliosis as a potential mechanism. Brain Res 804:331-336.

Andre V, Marescaux C, Nehlig A, Fritschy JM (2001) Alterations in hippocampal GABAergic system contribute to development of spontaneous recurrent seizures in the rat lithium-pilocarpine model of temporal lobe epilepsy. Hippocampus 11:452-468.

Behr J, Lyson KJ, Mody I (1998) Enhanced propagation of epileptiform activity through the kindled dentate gyrus. J Neurophysiol 79:1726-1732.

Behr J, Heinemann U, Mody I (2001) Kindling induces transient NMDA receptor-mediated facilitation of high-frequency input in the rat dentate gyrus. J Neurophysiol 85:2195-2202.

Bengzon J, Kokaia Z, Elmer E, Nanobashvili A, Kokaia M, Lindvall O (1997) Apoptosis and proliferation of dentate gyrus neurons after single and intermittent limbic seizures. Proc Natl Acad Sci USA 94:10432-10437.

Buhl EH, Han ZS, Lorinczi Z, Stezhka VV, Karnup SV, Somogyi P (1994) Physiological properties of anatomically identified axo-axonic cells in the rat hippocampus. J Neurophysiol 71:1289-1307.

Buhl EH, Otis TS, Mody I (1996) Zinc-induced collapse of augmented inhibition by GABA in a temporal lobe epilepsy model. Science 271:369-373.

Cain DP, Corcoran ME (1980) Kindling in the seizure-prone and seizureresistant Mongolian gerbil. Electroencephalogr Clin Neurophysiol 49:360-365.

Catalano SM, Shatz CJ (1998) Activity-dependent cortical target selection by thalamic axons. Science 281:559-562.

Cavazos JE, Sutula TP (1990) Progressive neuronal loss induced by kindling: a possible mechanism for mossy fiber synaptic reorganization and hippocampal sclerosis. Brain Res 527:1-6.

Cavazos JE, Golarai G, Sutula TP (1991) Mossy fiber synaptic reorganization induced by kindling: time course of development, progression, and permanence. J Neurosci 11:2795-2803.

Cavazos JE, Das I, Sutula TP (1994) Neuronal loss induced in limbic pathways by kindling: evidence for induction of hippocampal sclerosis by repeated brief seizures. J Neurosci 14:3106-3121.

Dalby NO, Mody I (2001) The process of epileptogenesis: a pathophysiological approach. Curr Opin Neurol 14:187-192.

Dalby N, West M, Finsen B (1998) Hilar somatostatin-mRNA containing neurons are preserved after perforant path kindling in the rat. Neurosci Lett 255:45-48.

de Jonge M, Racine RJ (1987) The development and decay of kindlinginduced increases in paired-pulse depression in the dentate gyrus. Brain Res 412:318-328.

During MJ, Ryder KM, Spencer DD (1995) Hippocampal GABA transporter function in temporal-lobe epilepsy. Nature 376:174-177. 
Freund TF, Buzsaki G (1996) Interneurons of the hippocampus. Hippocampus 6:347-470.

Goddard GV (1969) The development of epileptic seizures through brain stimulation at low intensity. Nature 214:1020-1021.

Goddard GV, McIntyre D, Leech C (1969) A permanent change in brain function resulting from daily electrical stimulation. Exp Neurol 25:295-330.

Gorter JA, van Vliet EA, Aronica E, da Silva FL (2001) Progression of spontaneous seizures after status epilepticus is associated with mossy fibre sprouting and extensive bilateral loss of hilar parvalbumin and somatostatin-immunoreactive neurons. Eur J Neurosci 13:657-669.

Gorter JA, van Vliet EA, Aronica E, da Silva FHL (2002) Long-lasting increased excitability differs in dentate gyrus vs. CA1 in freely moving chronic epileptic rats after electrically induced status epilepticus. Hippocampus 12:311-324.

Guillery RW, August B (2002) Doubt and certainty in counting. Prog Brain Res 135:25-42.

Halasy K, Somogyi P (1993) Subdivisions in the multiple GABAergic innervation of granule cells in the dentate gyrus of the rat hippocampus. Eur J Neurosci 5:411-429.

Hellier JL, Patrylo PR, Buckmaster PS, Dudek FE (1998) Recurrent spontaneous motor seizures after repeated low-dose systemic treatment with kainate-assessment of a rat model of temporal lobe epilepsy. Epilepsy Res 31:73-84.

Konigsmark B (1969) Methods for the counting of neurons. In: Contemporary research methods in neuroanatomy (Nauta W, Ebbeson S, eds), pp 315-340. Berlin: Springer.

Kotloski R, Lynch M, Lauersdorf S, Sutula T (2002) Repeated brief seizures induce progressive hippocampal neuron loss and memory deficits. Prog Brain Res 135:95-110.

Leranth C, Frotscher M (1986) Synaptic connections of cholecystokininimmunoreactive neurons and terminals in the rat fascia dentata: a combined light and electron microscopic study. J Comp Neurol 254:51-64.

Lothman EW, Stringer JL, Bertram EH (1992) The dentate gyrus as a control point for seizures in the hippocampus and beyond. Epilepsy Res Suppl 7:301-313.

Lynch M, Sutula T (2000) Recurrent excitatory connectivity in the dentate gyrus of kindled and kainic acid-treated rats. J Neurophysiol 83:693-704.

Majkowski J (1999) Kindling: clinical relevance for epileptogenicity in humans. Adv Neurol 81:105-113.

Mathern GW, Mendoza D, Lozada A, Pretorius JK, Dehnes Y, Danbolt NC, Nelson N, Leite JP, Chimelli L (1999) Hippocampal GABA and glutamate transporter immunoreactivity in patients with temporal lobe epilepsy. Neurology 52:453-472.

McNamara JO (1999) Emerging insights into the genesis of epilepsy. Nature 399:A15-A22.

Miles R, Toth K, Gulyas AI, Hajos N, Freund TF (1996) Differences between somatic and dendritic inhibition in the hippocampus. Neuron $16: 815-823$.

Mody I (1999) Synaptic plasticity in kindling. Adv Neurol 79:631-643.

Morrell F, Tsuru N (1976) Kindling in the frog: development of spontaneous epileptiform activity. Electroencephalogr Clin Neurophysiol 40:1-11.

Nusser Z, Hajos N, Somogyi P, Mody I (1998) Increased number of synaptic GABA(A) receptors underlies potentiation at hippocampal inhibitory synapses. Nature 395:172-177.

Oliver MW, Miller JJ (1985) Alterations of inhibitory processes in the dentate gyrus following kindling-induced epilepsy. Exp Brain Res 57:443-447.

Otis TS, De Koninck Y, Mody I (1994) Lasting potentiation of inhibition is associated with an increased number of gamma-aminobutyric acid type $\mathrm{A}$ receptors activated during miniature inhibitory postsynaptic currents. Proc Natl Acad Sci USA 91:7698-7702.

Parent JM, Janumpalli S, McNamara JO, Lowenstein DH (1998) Increased dentate granule cell neurogenesis following amygdala kindling in the adult rat. Neurosci Lett 247:9-12.

Penn AA, Shatz CJ (1999) Brain waves and brain wiring: the role of endogenous and sensory-driven neural activity in development. Pediatr Res 45:447-458.

Pinel JP, Rovner LI (1978) Experimental epileptogenesis: kindling-induced epilepsy in rats. Exp Neurol 58:190-202.

Pitkänen A, Nissinen J, Nairismägi J, Lukasiuk K, Gröhn O, Miettinen R, Kauppinen R (2002) Progression of neuronal damage after status epilepticus and during spontaneous seizures in a rat model of temporal lobe epilepsy. Prog Brain Res 135:67-84.
Pretel SAC, Piekut D (1997) Apoptotic and necrotic cell death following kindling induced seizures. Acta Histochem 99:71-79.

Represa A, Le Gall La Salle G, Ben-Ari Y (1989) Hippocampal plasticity in the kindling model of epilepsy in rats. Neurosci Lett 99:345-350.

Ribak CE, Seress L, Leranth C (1993) Electron microscopic immunocytochemical study of the distribution of parvalbumin-containing neurons and axon terminals in the primate dentate gyrus and Ammon's horn. J Comp Neurol 327:298-321.

Ribak CE, Tong WM, Brecha NC (1996) GABA plasma membrane transporters, GAT-1 and GAT-3, display different distributions in the rat hippocampus. J Comp Neurol 367:595-606.

Sayin U, Rutecki P, Sutula T (1999) NMDA-dependent currents in granule cells of the dentate gyrus contribute to induction but not permanence of kindling. J Neurophysiol 81:564-574.

Shin C, Pedersen HB, McNamara JO (1985) Gamma-aminobutyric acid and benzodiazepine receptors in the kindling model of epilepsy: a quantitative radiohistochemical study. J Neurosci 5:2696-2701.

Soltesz I, Smetters DK, Mody I (1995) Tonic inhibition originates from synapses close to the soma. Neuron 14:1273-1283.

Soriano E, Nitsch R, Frotscher M (1990) Axo-axonic chandelier cells in the rat fascia dentata: Golgi-electron microscopy and immunocytochemical studies. J Comp Neurol 293:1-25.

Stell BM, Mody I (2002) Receptors with different affinities mediate phasic and tonic $\mathrm{GABA}_{\mathrm{A}}$ conductances in hippocampal neurons. J Neurosci 22:RC223(1-5).

Stringer JL, Lothman EW (1989) Repetitive seizures cause an increase in paired-pulse inhibition in the dentate gyrus. Neurosci Lett 105:91-95.

Sutula T (2001) Secondary epileptogenesis, kindling, and intractable epilepsy: a reappraisal from the perspective of neural plasticity. Int Rev Neurobiol 45:355-386.

Sutula T, Steward O (1986) Quantitative analysis of synaptic potentiation during kindling of the perforant path. J Neurophysiol 56:732-746.

Sutula T, He XX, Cavazos J, Scott G (1988) Synaptic reorganization in the hippocampus induced by abnormal functional activity. Science 239:1147-1150

Sutula T, Lauersdorf S, Lynch M, Jurgella C, Woodard A (1995) Deficits in radial arm maze performance in kindled rats: evidence for long-lasting memory dysfunction induced by repeated brief seizures. J Neurosci 15:8295-8301.

Sutula T, Zhang P, Lynch M, Sayin U, Golarai G, Rod R (1998) Synaptic and axonal remodeling of mossy fibers in the hilus and supragranular region of the dentate gyrus in kainate-treated rats. J Comp Neurol 390:578 -594.

Sutula T, Sayin U, Knodel S, Rutecki P (2000) Seizure-induced loss of CCK and GAT-1 interneurons and reduced inhibition in the dentate gyrus: relationship to development of spontaneous seizures in kindled rats. Soc Neurosci Abstr 26:1050.

Swann JW, Smith KL, Lee CL (2001) Neuronal activity and the establishment of normal and epileptic circuits during brain development. Int Rev Neurobiol 45:89-118.

Tuff LP, Racine RJ, Adamec R (1983a) The effects of kindling on GABAmediated inhibition in the dentate gyrus of the rat. I. Paired-pulse depression. Brain Res 277:79-90.

Tuff LP, Racine RJ, Mishra RK (1983b) The effects of kindling on GABAmediated inhibition in the dentate gyrus of the rat. II. Receptor binding. Brain Res 277:91-98.

Wada JA, Osawa T, Mizoguchi T (1975) Recurrent spontaneous seizure state induced by prefrontal kindling in Senegalese baboons, Papio papio. Can J Neurol Sci 2:477-492.

Wada JA, Mizoguchi T, Osawa T (1978) Secondarily generalized convulsive seizures induced by daily amygdaloid stimulation in rhesus monkeys Neurology 28:1026-1036.

Wittner L, Magloczky Z, Borhegyi Z, Halasz P, Toth S, Eross L, Szabo Z, Freund TF (2001) Preservation of perisomatic inhibitory input of granule cells in the epileptic human dentate gyrus. Neuroscience 108:587-600.

Wuarin JP, Dudek FE (1996) Electrographic seizures and new recurrent excitatory circuits in the dentate gyrus of hippocampal slices from kainatetreated epileptic rats. J Neurosci 16:4438-4448.

Wuarin JP, Dudek FE (2001) Excitatory synaptic input to granule cells increases with time after kainate treatment. J Neurophysiol 85:1067-1077.

Zhu ZQ, Armstrong DL, Hamilton WJ, Grossman RG (1997) Disproportionate loss of CA4 parvalbumin-immunoreactive interneurons in patients with Ammon's horn sclerosis. J Neuropathol Exp Neurol 56:988-998. 